ОСОБЕННОСТИ СТРУКТУРНО-ФУНКЦИОНАЛЬНЫХ

ПОКАЗАТЕЛЕЙ СЕРДЕЧНО-СОСУДИСТОЙ СИСТЕМЫ У МУЖЧИН МОЛОДОГО ВОЗРАСТА С АРТЕРИАЛЬНОЙ ГИПЕРТОНИЕЙ В СОЧЕТАНИИ С МЕТАБОЛИЧЕСКИМ СИНДРОМОМ

\author{
Р.Т. Ризванова*, Н.И. Максимов \\ Ижевская государственная медищинская академия, Россия
}

\title{
PECULIAR FEATURES OF STRUCTURAL AND FUNCTIONAL INDICES OF CARDIOVASCULAR SYSTEM IN YOUNG MEN WITH ARTERIAL HYPERTENSION ASSOCIATED WITH METABOLIC SYNDROME
}

\author{
R.T. Rizvanova*, N.I. Maksimov \\ Izhevsk State Medical Academy, Russian Federation
}

\begin{abstract}
Цель. Оценить в динамике структурно-функциональные показатели сердечно-сосудистой системы у мужчин молодого возраста с артериальной гипертонией (АГ) в сочетании с избыточной массой тела на фоне терапии.

Материалы и методы. Обследовано 86 молодых мужчин в возрасте 18-27 лет, из которых в группу сравнения вошли практически здоровые $(n=24)$, а группу наблюдения $(n=62)$ составили пациенты с АГ без избыточной массы тела и в сочетании АГ с избыточной массой тела (Имт). Исследование проводилось исходно и через 6 месяцев лечения. Пациенты с АГ в сочетании с Имт $(n=25)$ распределились на две подгруппы: 1-я (12 человек) без терапии и 2-я (13) - на фоне антигипертензивной терапии.

Результаты. Через 6 месяцев в 1-й подгруппе отмечался рост «офисного» систолического АД на 3,8 \% $(145,0 \pm 2,88$ и 150,54 $\pm 2,99$ мм рт. ст.), $p=0,001$, а в подгруппе, где получали антигипертензивную терапию, наблюдалось снижение САД на 12,7 \% (145,75 $\pm 2,80$ и 129,33 $\pm 1,5$ мм рт. ст.), $p=0,01$; снижение ДАД - на 12,1 \% (86,5 $\pm 1,95$ и 77,16 $\pm 2,41$ мм рт. ст.), $p=0$ 0,02. Скорость распространения пульсовой волны (СРПВ) по сосудам мышечного и эластического типов: у пациентов без терапии в динамике наблюдался прирост на 12,2 и 16,2 \% соответственно. На фоне терапии прослеживалась тенденция достоверного снижения показателей СРПВ.

Выводы. Антигипертензивная терапия у пациентов с АГ в сочетании с избыточной массой тела, снижая АД, приводит к уменьшению массы миокарда левого желудочка, индекса массы миокарда левого желудочка, скорости распространения пульсовой волны и величины комплекса интима-медиа. Раннее определение поражения органов-мишеней у лиц молодого возраста при АГ в сочетании с избыточной массой тела и своевременная антигипертензивная терапия могут улучшить структурнофункциональные характеристики сердечно-сосудистых осложнений.
\end{abstract}

Ключевые слова. Артериальная гипертония, избыточная масса тела, медикаментозная терапия, величина комплекса интима-медиа, скорость распространения пульсовой волны.

( Ризванова Р.Т., Максимов Н.И., 2017

тел.: +79127573008

e-mail: talgatov@yandex.ru

[Ризванова Р.Т. ("контактное лицо) - ассистент кафедры госпитальной терапии; Максимов Н.И. - доктор медицинских наук, профессор, заведующий кафедрой госпитальной терапии с курсом функциональной диагностики ФПК и ПП]. 
Aim. To carry out dynamic assessment of the structural and functional indices of cardiovascular system in young men with arterial hypertension (AH) associated with excess body mass (Ebm) against the background of therapy.

Materials and methods. Examination of 86 young men aged 18-27 years, including the group of comparison with practically healthy persons $(n=24)$ and the group of observation $(n=62)$ was performed. The group of observation joined patients with AH without EBM and AH+EBM. The study was conducted initially and 6 months later. Patients with AH+EBM $(n=25)$ were divided into 2 subgroups: group 1 (12 persons) without therapy and group 2 (13 persons) against the background of antihypertensive therapy.

Results. Six months later, in group 1 there was observed a growth of "office" systolic arterial pressure (SAP) by $3,8 \%(145,0 \pm 2,88$ and $150,54 \pm 2,99 \mathrm{Hg} \mathrm{mm}), p=0,001$, but in the group with antihypertensive therapy, SAP decreased by $12,7 \%(145,75 \pm 2,80$ and $129,33 \pm 1,5 \mathrm{Hg} \mathrm{mm}), p=0,01$ and DAP - by $12,1 \%(86,5 \pm 1,95$ and 77,16 $\pm 2,41 \mathrm{Hg} \mathrm{mm}$ ), $p=0,02$. Pulse wave propagation velocity (PWPV) along the vessels of muscular and elastic types among patients without therapy was found to grow in dynamics by 12,2 and $16,2 \%$, respectively. Against the background of therapy, there was a tendency to a reliable reduction in PWPV indices. Conclusions. Antihypertensive therapy in patients with AH+EBM, while decreasing AP, leads to reduction of LVMM, LVMMI, PWPV and IMCV. The early diagnosed lesion of target organs among young men with $\mathrm{AH}+\mathrm{EBM}$ and timely antihypertensive therapy can improve structural and functional characteristics of cardiovascular complications.

Key words. Arterial hypertension, excess body mass, drug therapy, intima-media complex value, pulse wave propagation velocity.

\section{ВВЕДЕНИЕ}

В последние годы отмечается рост распространенности артериальной гипертонии (АГ) среди лиц молодого возраста [5, 7], причем избыточная масса тела (Имт) и ожирение являются самыми распространенными факторами риска ССЗ [1]. В России в среднем каждый 14-й мужчина (7,1%) в возрасте 20-29 лет имеет АГ, в возрасте 30-39 лет каждый 6-й (16,3 \%), в 40-49 лет - каждый 4-й (26,9\%), а в возрасте 50-54 лет этим заболеванием страдает уже каждый 3-й мужчина (34,4 \%). У лиц молодого возраста АГ в 50-60 \% случаев сочетается с метаболическими нарушениями $[9,10]$. Важную роль в патогенезе многих заболеваний сердечно-сосудистой системы играет повышение жесткости и снижение эластичности крупных артерий [8]. В настоящее время достаточно подробно представлены патофизиологические механизмы увеличения жесткости сосудов, показатели, определяющие артериальную жесткость у пациентов с изолированно проте- кающей АГ $[2,6]$. Длительное воздействие повышенного артериального давления (АД) на стенку сосудов приводит к дисфункции эндотелия, в результате чего возрастает тонус гладких мышц сосудов, запускаются процессы сосудистого ремоделирования [4]. Изучение состояния сосудистой стенки и функции эндотелия у больных артериальной гипертензией (АГ) молодого возраста является перспективным с позиций лечебного воздействия и профилактики сосудистых нарушений [3].

Цель исследования - оценить структурно-функциональные показатели сердечнососудистой системы у мужчин молодого возраста с АГ в сочетании с избыточной массой тела в динамике.

\section{МАТЕРИАЛ И МЕТОДЫ ИССЛЕДОВАНИЯ}

Работа проведена на базе Бюджетного учреждения здравоохранения Удмуртской Республики «Республиканский клиникодиагностический центр» М3 (г. Ижевск), 
в кардиологическом отделении № 2. Все пациенты представили письменное добровольное информированное согласие в соответствии с п. 4.6.1. приказа № 136 (ОСТ 91500.14.0001-2002) Министерства здравоохранения Российской Федерации, международными этическими требованиями ВО3, а также Хельсинкской декларацией Всемирной медицинской ассоциации (Этические принципы проведения медицинских исследований с участием людей в качестве объекта исследования, 1993). Обследовано 86 молодых мужчин в возрасте 18-27 лет за период 2013-2016 гг. В группу сравнения вошли практически здоровые $(n=24)$, а в группу наблюдения - с изолированной артериальной гипертонией и в сочетании с избыточной массой тела $(n=62)$. Исключались больные с симптоматической АГ, острым инфарктом миокарда, нестабильной стенокардией, сахарным диабетом, аутоиммунными заболеваниями, острой вирусной инфекцией. Группа наблюдения распределилась на две подгруппы: пациенты с артериальной гипертонией (АГ) без избыточной массы тела (Имт) и в сочетании АГ с Имт (АГ+Имт). Следующий этап исследования, в котором приняли участие 35 человек, проводился в динамике через 6 месяцев. Пациенты с АГ+Имт $(n=25)$ распределились на две подгруппы: 1-я группа $(n=12)$ - без терапии и 2-я $(n=13)$ - на фоне антигипертензивной терапии. Среди пациентов с изолированной АГ отмечена низкая приверженность к медикаментозной терапии.

Проводился клинический осмотр: анамнез (курение, наследственность), измерение объема талии (ОТ), артериального давления (АД); лабораторная диагностика: гликемия натощак, мочевая кислота, липидный спектр (ОХС, ТГ, ЛПНП, ЛПВП) и микроальбумины
(МАУ). Функциональная диагностика: электрокардиограмма (ЭКГ) - индекс СоколоваЛайона; эхокардиография (ЭхоКГ) - масса миокарда левого желудочка (ММЛЖ), индекс массы миокарда левого желудочка (ИММЛЖ), толщина задней стенки левого желудочка (ТЗСЛЖ), толщина межжелудочковой перегородки (ТМЖП); величина комплекса интимамедиа (ВКИМ) сонных артерий; скорость распространения пульсовой волны (СРПВ).

Полученные результаты подвергались статистической обработке с помощью программы Statistica 8.0. Для представления количественных признаков применяли значения среднего $(M)$ и стандартного отклонения $(S D)$. Для обработки результатов выборки использовали методы непараметрической статистики. Сравнения между двумя независимыми группами проводили по U-критерию Манна - Уитни.

\section{РеЗУЛЬТАТЫ И ИХ ОБСУЖДЕНИЕ}

По результатам исследования в 1-й группе пациентов наблюдался рост «офисного» систолического АД в динамике на 3,8 \% $(145,0 \pm 2,88$ и $150,54 \pm 2,99$ мм рт. ст. $)$, $p=0,001$, а в группе, где больные получали антигипертензивную терапию, отмечалось снижение САД на 12,7 \% (145,75 \pm 2,80 и $129,33 \pm 1,5$ мм рт. ст.), $p=0,01$; снижение ДАД - на 12,1 \% (86,5 \pm 1,95 и 77,16 $\pm 2,41$ мм рт. ст.), $p=0,02$. Пациенты с АГ в сочетании с повышенным Имт характеризуются более выраженными структурнофункциональными изменениями сердечнососудистых показателей, сдвигами параметров липидного спектра и уровнем гликемии крови по сравнению с изолированным течением данной нозологии. Общий холестерин (OXC), триглицериды (ТГ) достоверно были 
выше в группе с АГ+Имт (4,99 ммоль/л) в сравнении контрольной и группой с АГ без Имт. Липопротеины высокой плотности (ЛПВП) достоверно были ниже (1,04 ммоль/л) в сравнении с контрольной и группой с АГ без Имт. По уровню глюкозы крови группы были сопоставимы, хотя уровень глюкозы незначительно был выше у группы с АГ+Имт по сравнению с контрольной и группой наблюдения.

Определялись ранние признаки изменений функционального состояния сосудов с помощью методов ВКИМ, СРПВ. Результаты показали, что в группе пациентов с АГ+Имт на фоне нормальных значений ВКИМ сон- ных артерий СРПВ повышалась у лиц, не получающих постоянную терапию, в отличие от пациентов, принимающих антигипертензивные препараты. Ранние признаки ремоделирования сосудов (увеличение толщины комплекса интима-медиа общих сонных артерий, увеличение СРПВ и диастолическая дисфункция) являются предикторами сердечно-сосудистых осложнений при изолированной артериальной гипертонии и артериальной гипертонии в сочетании с избыточной массой тела.

Динамика структурно-функциональных изменений сердечно-сосудистой системы представлена в таблице.

\section{Динамика инструментальных методов исследования у мужчин молодого возраста с АГ в сочетании с избыточной массой тела (Имт)}

\begin{tabular}{|c|c|c|c|c|}
\hline \multirow[t]{2}{*}{ Показатель } & \multicolumn{2}{|c|}{$\begin{array}{c}\text { 1-я группа: } \\
\mathrm{A \Gamma}+\text { Имт, без терапии, } \\
n=13\end{array}$} & \multicolumn{2}{|c|}{$\begin{array}{c}\text { 2-я группа: } \\
\mathrm{AГ}+\text { Имт на фоне терапии, } \\
n=12\end{array}$} \\
\hline & первичный осмотр & через 6 месяцев & первичный осмотр & через 6 месяцев \\
\hline ЭКГ (индекс Соколова-Лайона), мм & $23,36 \pm 1,44$ & $23,90 \pm 1,11$ & $30,08 \pm 2,18^{*}$ & $23,25 \pm 1,77$ \\
\hline ЭхоКГ (ТЗСЛЖ), мм & $9,19 \pm 0,18$ & $9,90 \pm 0,20$ & $9,42 \pm 0,22$ & $9,12 \pm 0,15^{* *}$ \\
\hline ЭхоКГ (ТМЖП), мм & $9,23 \pm 0,20$ & $9,90 \pm 0,20$ & $9,50 \pm 0,22$ & $9,29 \pm 0,19^{*}$ \\
\hline ЭхоКГ (ММЛЖ), Г & $173,45 \pm 6,63$ & $193,0 \pm 7,45$ & $181,08 \pm 7,87$ & $172,08 \pm 6,49^{*}$ \\
\hline ЭхоКГ (ИММЛЖ), г/м² & $76,81 \pm 2,41$ & $89,09 \pm 3,89$ & $85,0 \pm 3,40$ & $80,66 \pm 2,94$ \\
\hline ВКИМ (ОСА $)$, мМ & $0,54 \pm 0,03$ & $0,58 \pm 0,02$ & $0,67 \pm 0,03$ & $0,55 \pm 0,03$ \\
\hline ВКИМ $\left(\mathrm{OCA}_{\text {биф }}\right)$, мм & $0,59 \pm 0,03$ & $0,73 \pm 0,05$ & $0,77 \pm 0,03^{* \text { *at }}$ & $0,65 \pm 0,03$ \\
\hline СРПВ $\left(\mathrm{C}_{\mathrm{N}}\right), \mathrm{M} / \mathrm{C}$ & $8,02 \pm 0,52$ & $9,00 \pm 0,91$ & $8,48 \pm 0,31$ & $7,33 \pm 0,25$ \\
\hline $\mathrm{CP} П \mathrm{~B}\left(\mathrm{C}_{3}\right), \mathrm{M} / \mathrm{C}$ & $6,73 \pm 0,30$ & $7,82 \pm 0,38$ & $7,31 \pm 0,27$ & $6,21 \pm 0,22^{* *}$ \\
\hline
\end{tabular}

П р и м е ч а н и е : достоверность различий в группах наблюдения: $*-p<0,05 ; * *-p<0,01 ; * * *-p<0,001$.

Индекс Соколова-Лайона по ЭКГ снизился у пациентов, принимающих антигипертензивную терапию, на 29,3%. При сравнении показателей ЭхоКГ: в 1-й группе - ТЗСЛЖ увеличилась на 7,2 \%, на фоне терапии уменьшение произошло на 3,3 \%. МмЛЖ во 2-й группе снизилась на 5,2\%. Показатели ВКИМ на стандартных участках были сопоставимы. В динамике СРПВ по сосудам мышечного и эластического типа у пациентов без терапии наблюдался прирост на 12,2 и 16,2 \% соответственно. У пациентов на фоне терапии прослеживалась тенденция достоверного снижения показателей СРПВ.

\section{Выводы}

1. Антигипертензивная терапия у пациентов с АГ в сочетании с Имт, снижая АД, приводит к уменышению ММЛЖ, ИММЛЖ, СРПВ и ВКИМ. 
2. Раннее определение поражения органов-мишеней у лиц молодого возраста с АГ в сочетании с Имт и своевременная антигипертензивная терапия могут улучшить структурно-функциональные характеристики сердечно-сосудистых осложнений.

\section{БИБЛИОГРАФИЧЕСКИЙ СПИСОК}

1. Акимова Е.В., Пушккарев Г.С., Гафаров В.В., Кузнецова В.А. Риск сердечнососудистой смерти в зависимости от показателя индекса массы тела у мужчин и женщин города Тюмени. Кардиологический журнал 2013; 3: 24-28.

2. Береснева Л.Н., Хлынова О.В., Туев А.В., Агафбонов A.B. Аорта как орган-мишень при коморбидности: артериальная гипертензия и кислотозависимая патология. Пермский медицинский журнал 2013; 3: 14-20.

3. Винокурова И.Г., Давидович И.М. Гендерные особенности ауторегуляции тонуса и жесткость сосудов у больных артериальной гипертензией молодого возраста. Дальневосточный медицинский журнал 2012; 2: 7-10.

4. Лишианов Ю.Б., Ефимова Н.Ю., Чернов В.И., Ефимова И.Ю., Калашникова Т.П. Роль дисфункции эндотелия и нарушения суточного профиля артериального давления в механизме развития цереброваскулярной недостаточности у пациентов с метаболическим синдромом. Российский кардиологический журнал 2013; 3: 6-11.

5. Лю К.М., Хлынова О.В. Неалкогольная жировая болезнь печени как модель па- циента с кардиоваскулярным риском. Международный научно-исследовательский журнал 2017; 5 (2): 147-151.

6. Макарова М.А.,Авдеев С.Н. Артериальная ригидность и эндотелиальная дисфункция у больных хронической обструктивной болезнью легких. Пульмонология 2011;4: 109-117.

7. Маянская С.Д., Гребенкина И.А., Кобалава ЖД. Структурно-функциональное ремоделирование стенки сосудов у лиц с анамнезом, отягощенным по артериальной гипертензии. Кардиология 2015; 2: 27-31.

8. Недогода С.В., Чаляби Т.А., Барыкина И.Н. Сосудистая жесткость и скорость распространения пульсовой волны как плацдарм и мишень для фармакотерапии. Вестник Волгоградского государственного медицинского университета 2012; 1:113

9. Олейников В.А., Матросова И.Б., Ясmребова Е.И., Фадеева С.С. Влияние гипертензии и метаболического синдрома на структуру и функции артерий. Международный медицинский журнал 2008; 1: 56-62.

10. Шальнова С.А., Деев А.Д., Баланова Ю.А., Капустина А.В., Константинов В.В., муромщев Г.А., Бойщов С.А. Динамика артериальной гипертонии в России: есть ли прогресс в назначении антигипертензивной терапии? (результаты исследований 19932013 гг.). Сердце 2015; 6: 389-396.

Материал поступил в редакцию 11.10.2017 